\title{
EL DERECHO COMO BIEN DE LA CULTURA. POR QUÉ ES ESTÉRIL EL DEBATE ENTRE POSITIVISMO JURÍDICO Y IUSNATURALISMO*
}

\author{
Joachim LEGE**
}

Resumen:

La antigua controversia entre el positivismo jurídico y la justicia natural resulta estéril si comprendemos al derecho como un fenómeno de la cultura. Consecuentemente, el derecho no es mera voluntad, ni tampoco razón pura. El derecho, como se entiende en la tradición occidental, es más bien un sistema contingente de reglas para la decisión (la política, en cambio, se guía por objetivos). La cultura, tal como es concebida desde la época de la Ilustración, puede describirse como "aquello que es resultado de la autonomía”. Como el derecho es un fenómeno valioso de la cultura (Kulturgut), entonces se plantean dos cuestiones: (1) ¿Hay necesidad del derecho? Ello depende de la demanda de libertad que tenga la sociedad. (2) ¿Qué necesita el derecho? El derecho requiere autonomía, es decir, el derecho a disfrutar de su propia cultura.

Palabras clave:

Derecho, cultura, autonomía, positivismo jurídico, iusnaturalismo.

* Texto anotado y ligeramente modificado de la lección inaugural dictada por el autor el 24 de junio de 2005 en la Facultad de Derecho de la Universidad de Greifswald, Alemania. El ensayo original apareció con el título de "Recht als Kulturgut”, Archiv für Rechts- und Sozialphilosophie, vol. 93, núm. 1, 2007, pp. 21-38. La traducción se publica con permiso del autor y de los editores de la revista. Traducción de Héctor Fix-Fierro.

** Profesor de la cátedra de derecho público, historia constitucional, y filosofía del derecho y el Estado de la Facultad de Derecho de la Universidad de Greifswald, Alemania. 


\section{JOACHIM LEGE}

Abstract:

The old controversy between Legal Positivism and Natural Justice turns out to be fruitless, if we comprehend law as a phenomenon of culture. Then, law is neither mere will nor mere reason. Law, as it is understood in the Western tradition, is rather a contingent system of rules which guides decisions (politics, on the other hand, are guided by aims). Culture, as it is conceived since the age of Enlightenment, can be described as "what results from autonomy". Law being a valuable phenomenon of culture (Kulturgut), two questions arise. (1) Is there any need for law? It depends on society's demand for liberty. (2) What does the law need? Law requires autonomy, i.e., the right to enjoy its own culture.

Keywords:

Law, Culture, Autonomy, Legal Positivism, Natural Law. 
SumARIO: I. ¿Derecho natural contra positivismo? II. Derecho y cultura: clarificaciones conceptuales. III. El derecho como cultura y lo que de ello se sigue. IV. El derecho como bien de la cultura. V. Resumen y observaciones finales.

\section{I. ¿DERECHO NATURAL CONTRA POSITIVISMO?}

La idea en que se basa esta lección inaugural se remonta a un encuentro interdisciplinario en la Universidad de Greifswald, Alemania. En noviembre de 2004 recibimos la visita del politólogo Dieter Hüning, de Marburgo, quien dictó una conferencia sobre el ius puniendi, esto es, el derecho de castigar, y su fundamentación a comienzos de la era moderna. Hüning examinó las ideas de Hobbes y Locke, pero lo interesante fue que primero expuso la postura del autor posterior, es decir, de John Locke (1633-1704), y luego la de Thomas Hobbes (1588-1679). En el Second Treatise of Government (1689), Locke dice que en el estado de naturaleza, es decir, antes de la creación del Estado, todo hombre posee un derecho punitivo natural. Cada uno es juez en su propia causa, e incluso juez en la causa de otros o de la colectividad. Y esto es válido no sólo para la declaración del derecho, sino también para su ejecución. ${ }^{1}$

Para Hobbes, en cambio, en el estado de naturaleza no hay derecho en sentido normativo, sino sólo leyes naturales, en el sentido de la ciencia natural y la sociología. En el Leviatán (1651) se lee: todos tienen "derecho" a todo en la medida que lo puedan obtener y defender. De ello se deriva la guerra de todos contra todos. En la vida de los seres humanos no hay entonces lugar para la cultura - Hobbes menciona solamente "the culture of the earth", la agri-cultura-, porque nadie tiene seguros los frutos de su industria. Por tanto, la vida humana es "solitaria, miserable, brutal y breve”. Para superar este estado, los hombres aceptan finalmente dos "leyes de la naturaleza", es decir, dos reglas 
de supervivencia. La primera dispone: "busca la paz y atente a ella mientras haya esperanza". La segunda señala: "renuncia voluntariamente a tu derecho a todo, si los demás también lo hacen". Sobre esta base, los seres humanos crean el Estado al someterse a un poder soberano. Es el Estado entonces el primero que en su nombre define el derecho y los derechos, por ejemplo, la propiedad y el delito. ${ }^{2}$

En el debate que siguió a la conferencia se sostuvo la tesis de que Locke, en contra de un extendido prejuicio, no estaba más avanzado que Hobbes. De acuerdo con una interpretación común, Hobbes es el gran teórico del poder absoluto del Estado, incluso del Estado en todo su horror -él mismo lo calificó como "Leviatán" es decir, le dio el nombre de un monstruo bíblico-. Además, Hobbes es el gran positivista, pues para él auctoritas, non veritas facit legem (la autoridad, el autor, hace las leyes, no la verdad). ${ }^{3}$ En cambio, Locke es el gran teórico del lado soleado del derecho natural, de los derechos humanos innatos, del derecho a la vida, la libertad y la propiedad, de la división de poderes. ${ }^{4}$ Pero vistas las cosas con más cuidado, así la tesis en el debate de entonces, en sus premisas sobre el estado de naturaleza Locke es, primero, más conservador, y segundo, prácticamente ingenuo -ingenuo en suponer que el derecho y el orden jurídico se dan, por así decirlo, de manera espontánea, "natural"- sin una autoridad que los garantice-.

En esa oportunidad yo tomé nota de dos pequeñas ideas. La primera decía: "por qué es estéril el debate entre iusna-

2 Hobbes, Thomas, Leviathan, 1651, caps. 13, 14, 17 y 18.

3 Hobbes, Leviathan, en Opera philosophica, ed. Molesworth (1839-1845), reimpr. Aalen 1961, cap. 26, p. 203.

4 Locke, op. cit., nota 1, en especial V (La propiedad), VII 85 y 87, IX (E1 fin principal de la sociedad civil es la conservación de la "propiedad" en el sentido de "life, liberty, estate"), XI y siguientes (División de poderes, pero como tercer poder no aparece el judicial, sino el federativo, es decir, la competencia de representación hacia el exterior; además, a través de la llamada prerrogativa se reconoce una especie de competencia para casos de excepción). Sobre los lados oscuros, véase V: Una justificación de la colonización de América del Norte. 
turalismo y positivismo jurídico".5 La segunda: "sustituye "naturaleza por cultura", esto en referencia a la formación aparentemente natural y espontánea del orden social. Desde ahí no había mucha distancia a la idea, poco sensacional, de que el derecho es y ha sido siempre cultura.

Pero como seguramente saben los lectores del libro The Hitchhiker's Guide to the Galaxy, por cierto, un libro de culto, es mucho más sencillo encontrar respuesta a la gran pregunta por el todo, y obtener de algún modo respuesta, que plantear con precisión la pregunta - en el libro la respuesta es " 42 "- 6 Por ello debemos intentar encontrar la pregunta adecuada para la cual la gran respuesta es "el derecho es cultura”. Para decirlo con Reinhold Zippelius, ${ }^{7}$ permítasenos experimentar un poco. Quizá la pregunta adecuada en la actualidad sea la siguiente: “¿necesitamos el derecho?”. Pero la pregunta también puede ser: “¿qué necesita el derecho?".

\section{DERECHO Y CULTURA: CLARIFICACIONES CONCEPTUALES}

Al comienzo de toda ciencia se encuentra, siguiendo a Hobbes, la clarificación de los conceptos con los que se pretende trabajar, y el primer abuso de la ciencia consiste, de acuerdo también con Hobbes, en que no proponga definiciones, o las definiciones sean falsas. ${ }^{8}$ Es difícil ciertamente definir conceptos tales como los de "derecho" y "cultura”. Si tomamos el concepto de "derecho": cuando una ley, una sentencia judicial, o simplemente una situación social re-

5 En forma atenuada, esta tesis de la esterilidad ya se encuentra en Hollerbach, Alexander, voz "Rechtswissenschaft", en Staatslexikon, ed. por la Görres-Gesellschaft, 7a. ed., vol. 4, 1988, col. 757; idem, Ausgewählte Schriften, ed. por Gerhard Robbers, Berlín, Duncker und Humblot, 2006, p. 93.

6 Adams, Douglas, The Hitchhiker's Guide to the Galaxy, Londres, Pan Books, 1979, caps. 27 y siguiente.

7 Zippelius, Reinhold, Rechtsphilosophie, 4a. ed., Munich, C.H. Beck, 2003, § 11 III; "Die experimentierende Methode im Recht”, en idem, Recht und Gerechtigkeit in der offenen Gesellschaft, 2a. ed., Berlín, Duncker und Humblot, 1996, pp. 21 y ss.

8 Véase Hobbes, op. cit., nota 2, cap. 4 (“De la lengua”). 
sultan insoportablemente injustas - piensen en la esclavitud, los procesos contra las brujas o las leyes raciales de Nuremberg - ¿podemos decir que "son" todavía derecho, aunque sea un derecho injusto?, ¿o es acaso "no-derecho", sólo un derecho aparente, violencia bajo el manto del derecho? Tomemos ahora el concepto de "cultura": ¿la música y el blablablá que se oye todos los días en el llamado radio de formato son cultura, o la cultura comienza a partir, digamos, de Mozart?, ¿se trata de cultura, política o religión cuando una maestra musulmana viste el velo?, ¿y qué se deduce de ello?

Según parece, los conceptos de "derecho" y "cultura" poseen distintos significados en diversos contextos. Por supuesto, no se trata de ninguna particularidad suya, sino que eso se observa también en otros conceptos. El ejemplo más famoso entre los filósofos es el concepto de "juego". Ludwig Wittgenstein mostró, gracias a él, que algunos conceptos no pueden comprenderse a través de una definición, sino solamente a través de parecidos de familia. ${ }^{9}$

\section{Parecidos de familia}

\section{Wittgenstein escribe:}

Considera, por ejemplo, los procesos que llamamos "juegos". Me refiero a juegos de tablero, juegos de cartas, juegos de

9 Este enfoque se asemeja al pensamiento tipificador, a la elaboración de conceptos típicos; véase al respecto Zippelius, Reinhold, "Typisierendes Denken”, en idem, Recht und Gerechtigkeit..., cit., nota 7, pp. 411 y ss.; además, del mismo autor, Allgemeine Staatslehre, 14a. ed., Munich, C.H. Beck, 2003, § 2 III (hay traducción española de la 10a. ed. alemana: Teoría general del Estado, México, UNAM-Porrúa, 1988); idem, Juristische Methodenlehre, 9a. ed., Munich, C.H. Beck, 2005, § 12.

Sobre el significado del concepto de tipo a la luz de Wittgenstein, véase Kindhäuser, Urs, "Zur Definition qualitativer und komparativer Begriffe", Rechtstheorie, año 12, 1981, pp. 226 y ss. Quizá haya también similitudes con la llamada fuzzy logic, $c f r$. al respecto Philipps, Lothar, "Ein bißchen Fuzzy Logic für Juristen”, en Tinnefeld, Marie-Theres et al. (eds.), Institutionen und Einzelne im Zeitalter der Informationstechnik. Machtpositionen und Rechte, Munich-Viena, Oldenbourg, 1994, pp. 219 y ss. 
pelota, juegos de lucha, etc. ¿Qué hay común a todos ellos? -No digas: "Tiene que haber algo común a todos ellos o no los llamaríamos 'juegos"” - sino mira si hay algo común a todos ellos-. Pues si los miras no verás por cierto algo que sea común a todos, sino que verás semejanzas, parentescos y por cierto toda una serie de ellos. Como se ha dicho: ¡no pienses, sino mira!... ¿Son todos ellos "entretenidos"? Compara el ajedrez con el tres en raya. ¿O hay siempre un ganar y perder, o una competición entre los jugadores? Piensa en los solitarios. En los juegos de pelota hay que ganar y perder, pero cuando un niño lanza una pelota a la pared y la recoge de nuevo, ese rasgo ha desaparecido... Piensa ahora en los juegos de correr. Aquí hay el elemento del entretenimiento, ipero cuántos de los otros rasgos característicos han desaparecido!... Y el resultado de este examen reza: vemos una complicada red de parecidos que se superponen y entrecruzan. Parecidos a gran escala y de detalle.

No puedo caracterizar mejor esos parecidos que con la expresión "parecidos de familia", pues es así como se superponen y entrecruzan los diversos parecidos que se dan entre los miembros de una familia: estatura, facciones, color de ojos, andares, temperamento, etc., etc.- Y diré: los "juegos" componen una familia. ${ }^{10}$

Mi tesis es la siguiente: también los conceptos de "derecho" y de "cultura" designan, respectivamente, una familia de diversos - dudo en decir "derechos" y "culturas", por lo que digo mejor: diversas concepciones ${ }^{11}$ de derecho y cultura-. Al igual que Wittgenstein, pretendo primeramente echar una ojeada, para ver quién o qué pertenece a estas familias. En un paso más adelante deseo saber más sobre

10 Wittgenstein, Ludwig, Philosophische Untersuchungen, núms. 66, 67 (versión española: Investigaciones filosóficas, trad, de Alfonso García Suárez y Ulises Moulines, Madrid, Ediciones Altaya, 1999).

11 Sobre la contraposición entre "concept" y "conception" en Ronald Dworkin, véase Bittner, Claudia, Recht als interpretative Praxis. Zu Ronald Dworkins allgemeiner Theorie des Rechts, Berlín, Duncker und Humblot, 1988, pp. 26 y ss. 
estas familias, mientas cuento su historia. Un tercer paso consistirá, por así decirlo, en decidirse a favor de una determinada concepción de derecho y de cultura.

\section{Derecho}

¿Qué es derecho? Consideremos primero las múltiples características que se asocian con el concepto de derecho, y preguntemos si les corresponde a todas lo que denominamos derecho. (1) ¿Corresponde al derecho, a diferencia de la costumbre, poder ser aplicado coactivamente? No, piénsese en el $\S 888$, inciso 3, del Código Procesal Civil alemán $(\mathrm{ZPO})^{12}$ y en el derecho internacional público clásico. (2) ¿Tiene que ver el derecho, en contraste con la moral, solamente con comportamientos externos, no con los motivos internos? No, el homicidio simple se vuelve calificado en virtud de las "bajas motivaciones" (§ 211 del Código Penal alemán). (3) ¿Pertenece al derecho la existencia de una instancia neutral que resuelva de manera imparcial? No, si se piensa en John Locke y el derecho en el estado de naturaleza, en el que cada quien lo declara y lo ejecuta. (4) ¿Corresponde al derecho el que tenga la pretensión de ser correcto? No, Thomas Hobbes dice auctoritas, non veritas facit legem. (5) ¿Tiene entonces el derecho que ver necesariamente con el Estado? No, piénsese en la Liga Hanseática y en la lex mercatoria de los mercados internacionales actuales. ${ }^{13}$ (6) ¿Forma parte del derecho el contar con una administración de justicia especializada? No, en muchas sociedades no es posible distinguir claramente entre derecho, costumbre, religión, moral y política, sino que éstos se traslapan; piénsese no sólo en los pueblos "primitivos" o en el Islam, sino también en la antigua Atenas o en la temprana Edad

12 De acuerdo con este precepto, la condena judicial a la celebración del matrimonio o a la convivencia conyugal no puede ser ejecutada coactivamente mediante medidas apremio (multa o prisión).

13 Véase Stein, Ursula, Lex mercatoria, Frankfurt a.M., Vittorio Klostermann, 1995. 
Media. ¿Es que existe "en absoluto” el derecho en tales sociedades?, ¿o podemos decir que se trata (todavía) de derecho, pero de una "especie completamente distinta"?

Según parece, tratándose de aquello que el ser humano denomina "derecho" —o "law", "Recht", "droit", "diritto", "pravo" - solamente es posible constatar parecidos de familia. Lo que sea concretamente el derecho es algo que se deriva apenas del contexto social e histórico completo, en el que ha de leerse el texto especial del "derecho" (traducido literalmente, "texto" significa "tejido"). Se puede decir, por ejemplo, que el derecho tiene que ver siempre con conflictos y con un cierto modo de resolverlos. Una vez dado este primer paso podemos ser estrictos y definir (7): el modo específico como el derecho soluciona conflictos consiste en decidir y, al hacerlo, formula una regla, es decir, un programa condicional ${ }^{14}$ conforme al esquema "si X, entonces Y" ("el que le saque un ojo a otro, será castigado”). Sin embargo, no tenemos que ser tan estrictos: una asamblea tribal en la que el pleito por un cerdo robado se resuelve matando al animal para una fiesta de reconciliación, es una forma de resolución de conflictos a la que podemos denominar "derecho", aunque sea quizá derecho "primitivo". ${ }^{15}$

La transacción judicial no es mucho más elevada. De acuerdo con el $\S 278$, inciso 1, enunciado 1 del Código Procesal Civil alemán (ZPO), los tribunales tienen que considerar "en cualquier etapa del procedimiento, la solución voluntaria de la controversia jurídica”; desde 2002 existe inclusive una audiencia obligatoria de conciliación. ${ }^{16}$ Pero

14 Sobre el programa condicional como característica esencial del derecho véase Luhmann, Niklas, Das Recht der Gesellschaft (traducción El derecho de la sociedad, México, UIA, 2002, pp. 253, 258 y s., 260), 1993, pp. 195, 199 y s., 201; véase también, en principio, Gröschner, Rolf et al., Rechts- und Staatsphilosophie. Ein dogmenphilosophischer Dialog, Berlín-Heidelberg-Nueva York, Springer, 2000, § 3.

15 Cfr. Pawlowski, Hans-Martin, Methodenlehre für Juristen. Theorie der Norm und des Gesetzes, 3a. ed., Heidelberg, C. F. Müller, 1999, núms. marginales 37 y ss. (43), quien utiliza la "justicia de cadî" precisamente como modelo opuesto al método jurídico racional.

16 Sobre los antecedentes, véase Leipold, Dieter, en Stein-Jonas, ZPO, 21 a. ed., 1996, § 279, núms. marginales 1-6. En el año de 1924 fue la primera vez que se in- 
si la esencia del derecho consistiera solamente en decidir un caso con base en una regla, ${ }^{17}$ entonces la transacción judicial no sería verdaderamente "derecho", pues, si bien ésta resuelve un conflicto, es sólo el conflicto concreto, pero no regula el conflicto abstracto. Así, la transacción judicial persigue solamente un objetivo concreto, a saber, que las partes se entiendan nuevamente, pero evade la regla y la decisión. ${ }^{18}$ Sin embargo, la conducta con arreglo a fines - sigo aquí a Luhmann - no es justamente la esencia del derecho, sino la de la política y, por tanto, también de la administración (la que, para Luhmann, forma parte del sistema político). ${ }^{19}$ Por tanto, la transacción judicial es una especie de administración para la conciliación. ${ }^{20}$ No se trata de derecho en sentido material, sino sólo en sentido formal, ${ }^{21}$ porque los órganos impartidores de justicia son los "actores" principales.

Resumimos: la estructura condicional del enunciado jurídico tampoco corresponde a todo lo que denominamos "de-

trodujo una audiencia de conciliación obligatoria, la que, sin embargo, no funcionó bien (sobre Berlín y Weimar, véase la nota 92, infra).- Sobre la nueva situación jurídica, véase la opinión crítica de Hartmann, Peter, en Baumbach/Lauterbach/Albers/Hartmann, ZPO, 63a. ed., 2005, § 275, núm. marginal 8: "En realidad, todo esto es indigno del tribunal" (énfasis en el original). Por el contrario, el legislador justificó la novedad señalando que en los tribunales prevalece "una insuficiente cultura de solución de los conflictos" (!); véase Foerste, Ulrich, en Musielak, ZPO, 4a. ed., 2005, § 278, núm. marginal 1. Dicho en otras palabras: en los tribunales existe todavía demasiada cultura jurídica.

17 Que la regla sea "aplicada" o "desarrollada" es una cuestión secundaria que se refiere a la oposición entre derecho legislado y derecho casuístico, la cual no es tan grande. Cfr. Zippelius, Rechtsphilosophie, cit., nota 7, § 18.

18 Por tanto, cuando la doctrina señala unánimemente, en relación con el § 278 $Z P O$, que el propósito de esta disposición es la "paz jurídica", está en un error: el único propósito es la paz, aunque ello vaya incluso a costa del derecho.

19 Véase Luhmann, op. cit., nota 14, pp. 424, 431.

20 Cfr. Lege, Joachim, Pragmatismus und Jurisprudenz, Tubinga, Mohr-Siebeck, 1999, p. 581. Desde el punto de vista de la historia del derecho, hay que señalar que la separación entre justicia y administración es una conquista de la era moderna, la cual, por supuesto, puede volver a perderse.

21 Cfr. sobre el concepto de administración en sentido material —ejercicio de las tareas de la administración pública - y de administración en sentido formal — toda la actividad de las autoridades administrativas- veáse Maurer, Hartmut, Allgemeines Verwaltungsrecht, 15a. ed., Munich, C. H. Beck, 2004, § 1, núms. marginales 2 y ss. 
recho", pero sí se atribuye a lo que nosotros entendemos históricamente, en su núcleo, por derecho. Enunciados del tipo "A quien robe un buey se le cortará la mano" se encuentran en el Código de Hammurabi, en el Talmud, etcétera. La colección más influyente de enunciados de esta clase es el Corpus Iuris Civilis, el texto clásico del derecho romano. Desde entonces se agrega a lo que consideramos derecho una característica más, a través de la cual nosotros nos distinguimos de la familia de todos los derechos (8): la elaboración sistemática. El derecho es un sistema de reglas, de enunciados condicionales, que es preciso estudiar cuidadosamente antes de poder colaborar profesionalmente en su producción - tan cuidadosamente como se estudia la medicina, la teología o la música-. Esto en nada cambia el que, como observador externo, se pueda juzgar si la producción es exitosa. Como dice Hegel: no es necesario ser zapatero para saber si los zapatos te quedan bien. ${ }^{22}$

En vista de todo lo anterior, quizá podamos retener lo siguiente: para nosotros, es decir, así como lo entendemos en nuestra cultura, el derecho se caracteriza fundamentalmente por (7) la existencia de reglas abstractas y (8) la elaboración sistemática por el lado de los productores. Aunque no siempre, pero en lo fundamental forman parte de él: la exterioridad (2), la coacción legítima (1) y quizá también una pretensión de corrección (4).

\section{Cultura}

¿Qué es cultura? Consideremos aquí, inicialmente, los fenómenos que están asociados con el término: (1) cultura proviene del latín colere (colo, coluim, cultum), cuyo significado principal es el de "cultivar". En este significado originario significa cultura sobre todo el cultivo de la tierra, la agri-cultura. En este sentido cultura y cultivar quiere decir: dejar crecer, de tal modo que algo se logre bien de acuerdo

22 Hegel, Georg Wilhelm Friedrich, Grundlinien der Philosophie des Rechts (1821), § 215, corolario, en Werkausgabe, 1970, vol. 7, p. 368. 
con sus propias leyes. (2) Justamente lo contrario sucede (estoy exagerando) cuando un ser humano es cultivado. Cuando tiene cultura, entonces el ser humano no despliega sus comportamientos naturales, sino que se orienta conforme a las normas de la sociedad, inclusive las de la alta sociedad. Cultivado significa tanto como civilizado, en contraposición a lo campesino-natural, y la cultura quiere decir tanto como instrucción. (3) Por tanto, cultura parece tener que ver algo con lo elevado, espiritual, excelente; en suma, con la elite. Así, hasta la Primera Guerra Mundial, los pueblos de Europa tenían la plena certeza de ser naciones de cultura o civilizadas, es decir, se consideraban mejores que el resto del mundo. (4) Por el otro lado, también existe una cultura antielitista: la cultura "pop"; piénsese sobre todo en la cultura "punk". (5) El "punk" no es sólo un tipo de música y una moda del vestir, sino que también se presenta como subcultura, como estilo de vida. ${ }^{23}$ En este sentido de "estilo de vida" es que el concepto de cultura aparece también en plural: hay culturas de las diversas naciones, también de los grupos de población, las cuales comprenden inclusive la cultura jurídica. (6) Por otro lado, y sobre todo cuando pensamos en la sección de cultura de un periódico, la cultura abarca sobre todo el ámbito de las artes: la música, el teatro, el cine, los medios de comunicación. (7) Pero no sólo eso: si consultamos el manual de Derecho del Estado de Zippelius y Würtenberger en el apartado sobre "Constitución de la cultura" ("Kulturverfassung"), vemos que comprende no sólo la radio y la televisión, sino también las escuelas y la educación superior. ${ }^{24}$ En este sentido, la "cul-

23 Cfr. Soeffner, Hans Georg, "Stil und Stilisierung. Punk oder die Überhöhung des Alltags", en Gumbrecht, Hans-Ulrich y Pfeiffer, K. Ludwig (eds.), Stil. Geschichten und Funktionen eines kulturwissenschaftlichen Diskurselements, Frankfurt a. M., Suhrkamp, 1986, pp. 317 y ss.; véase también Feyerabend, Paul, Wissenschaft als Kunst, Frankfurt a. M., Suhrkamp, 1984, p. 78. Más actual, culturalmente hablando: Ismer, Sven y Kronast, Stefanie, "Chronic Failure at School as a Source of Shame - Hip Hop Culture as a Space for Adolescents to Cope with Discrimination", ZiF:Mitteilungen 4/2005, pp. 7 y ss.

24 Zippelius, Reinhold y Würtenberger, Thomas, Deutsches Staatsrechts, 31a. ed., Munich, C. H. Beck, 2005, § 36. 
tura" tiene que ver nuevamente, aunque de manera sublimada, con la crianza, no del ganado, sino de los seres humanos. (8) La palabra "culto" refiere finalmente a la relación de la cultura con la religión, con lo que es digno de honra, con el ritual - lo que se manifiesta también en expresiones como película o automóvil "de culto"-.

La historia del concepto moderno de cultura es relativamente reciente (por lo que quizá "cultura" significa más o menos lo mismo en todas las lenguas) y comprende en lo esencial tres épocas. ${ }^{25}$ (1) Originalmente, la cultura, en francés, era sinónimo de civilización, que era un concepto de la Ilustración para designar el progreso que había traído consigo la burguesía en el ámbito intelectual, espiritual, político y material. (2) A partir de la crítica a este progreso, y en especial a la tendencia imperial de las naciones "civilizadas", surgió el concepto de "cultura" justamente como su opuesto, en Alemania, marcado sobre todo por Johann Gottfried Herder. "Cultura" significa entonces algo así como la forma de vida de un pueblo, sea una nación o algún otro pueblo "primitivo". En este sentido, cultura tiene, primeramente, algo de grave y melancólico, es algo "crítico y elevado”, es decir, típicamente alemán, ${ }^{26}$ pero también tiene algo plural, pues existen diversas culturas. (3) A comienzos del siglo XIX el concepto de cultura da un nuevo giro y se especializa en las artes, las cuales se diferencian en esta época como subsistema autónomo de la sociedad: con museos, teatros permanentes, salas de conciertos, y la bohemia artística. ${ }^{27}$ Entre estos tres significados (civilización, forma de vida, arte) se mueve el concepto de cultura hasta la fecha. La llamada postmodernidad ha conseguido simplemente que la cultura quiera decir cualquier cosa que se apoye en la costumbre o la tradición, como puede ser una cultura

25 En lo que sigue Eagleton, Terry, Was ist Kultur?, 2a. ed., Munich, C. H. Beck, 2001, pp. 17 y ss. (original: The Idea of Culture, 2000; versión española de Ramón del Castillo, La idea de la cultura. Una mirada politica sobre los conflictos culturales, Barcelona, Paidós, 2001).

26 Véase Eagleton, op. ult. cit., p. 19.

27 Lege, op. cit., nota 20, pp. 313 y ss., con mayores referencias. 
carcelaria o la "cultura del mirar para otro lado". Pero sobre todo se da un uso político al concepto en relación con las minorías y sus derechos: el derecho humano a "disfrutar de la cultura propia” fue motivo de múltiples referencias recientemente en el Congreso Mundial de la Asociación Internacional de Filosofía del Derecho en Granada (2005). ${ }^{28}$

Este último giro hace referencia a algo que quizá es sumamente esencial, algo que se encuentra detrás de la idea de cultura, pero sin que pueda definirla: la autonomía. Por ello, queremos sentar las bases para lo que sigue mediante la tesis de que la cultura es algo que se sigue de la autonomía, algo que surge a partir de ella y que Hegel denomina "espíritu objetivo". 29

Si desde esta perspectiva echamos de nuevo una mirada a la historia de familia del concepto de cultura, resulta evidente que la "cultura como Ilustración" se concebía como autónoma, con su concepto ofensivo de libertad, mientras que la "cultura como forma de vida" se entiende a partir del concepto defensivo de libertad del "déjame en paz". El giro hacia la cultura como arte se explica quizá por el hecho de que en este ámbito se ha vivido de manera especialmente intensa la emancipación, la liberación frente a la religión y el Estado. Las dificultades se plantean únicamente con los sentidos originales: ¿qué tiene que ver la agricultura y la cultura como educación con la autonomía? Bien: auto-nomía significa, literalmente, ley propia. La ley es, como dice Tomás de Aquino, una especie de regla o medida (regula vel mensura). Como tal, la regla puede "estar en alguien" de doble manera: "la primera como en quien mide y regula" (de modo activo), lo cual es cuestión de la razón (ratio); por la otra, "como en aquello que es medido o regula-

28 En particular por Will Kymlicka en la ponencia The Moral Foundations and Geopolitical Functions of International Norms of Minority Rights: A European Case Study; las memorias del Congreso no están publicadas todavía.

29 Agradezco esta referencia a Kurt Seelmann; igualmente Sprenger, Gerhard, "Recht als Kulturerscheinung", Archiv für Rechts- und Sozialphilosophie, vol. 43, 1991, p. 134 (146), con una cita de Heinrich Rickert. 
do". 30 En este segundo modo es que la ley de la gravedad "está" en la piedra ${ }^{31}$ y la ley para crecer, florecer y dar fruto "está” en el árbol, en el cereal, pero también en el ser humano, sea de manera física o espiritual. En el ámbito de la agricultura y la educación significa cultura, por tanto, respetar, e incluso promover y desarrollar para el bien común, la autonomía del objeto, es decir, su ley propia.

\section{El DERECHO COMO CULTURA Y LO GUE DE ELLO SE SIGUE}

La consecuencia para nuestro contexto es evidente: si el derecho es un pedazo de la cultura, entonces también le corresponde un pedazo de autonomía. Esto se puede entender en un sentido descriptivo, pero también normativo: para merecer ese nombre, el derecho debe gozar de suficiente autonomía. Pero para que esta conclusión pueda convertirse en exigencia, tenemos que examinar con cuidado el supuesto de hecho: ¿es verdaderamente el derecho un pedazo de la cultura?

\section{El derecho como cultura versus positivismo e iusnaturalismo}

Por lo pronto podemos recurrir a las autoridades. ${ }^{32} \mathrm{La}$ ciencia jurídica alemana de fines del siglo XIX y comienzos del XX entendía el derecho, incluso en grado excesivo, como manifestación cultural y, por ello, concebía a la propia ciencia jurídica como ciencia cultural. Por el lado de la filosofía del derecho son sobre todo los nombres de Emil Lask, Ru-

30 Aquino, Tomás de, Summa theologica I-II (1266-1273) cuestión 90, artículo 1o.; ahí se habla sobre la "ley en los miembros", es decir, los impulsos humanos.

31 En términos similares, aunque más diferenciados, el filósofo estadounidense Charles Sanders Peirce (1839-1914). Véase al respecto Lege, op. cit., nota 20, por ejemplo, pp. 272 y ss., 511.

32 Sobre lo que sigue, véase las reflexiones básicas de Sprenger, op. cit., nota 29. 
dolf Stammler y Gustav Radbruch los que representan esta corriente. Desde el punto de vista filosófico se sustentan principalmente en el neokantismo de Wilhelm Windelband y Heinrich Rickert y en su intento de afirmar el lugar de las ciencias del espíritu y la cultura frente a las ciencias naturales en expansión. El argumento era que la "naturaleza" era entendida e investigada por las ciencias naturales como un objeto exento de valor; en cambio, la "cultura", como algo con valor, es objeto de las ciencias del espíritu. ${ }^{33}$ En la Filosofia del derecho de Radbruch se afirma: "El concepto de derecho es un concepto cultural, o, lo que es lo mismo, un concepto de una realidad referida a valores. El derecho es la realidad que tiene el sentido de servir al valor, a la idea del derecho" - y por idea del derecho entiende Radbruch la justicia-. ${ }^{34}$ Más adelante dice sobre la lógica de la ciencia jurídica, entendida ésta como "ciencia cultural comprensiva":

Y no sucede cosa diferente en el mundo espiritual que en el mundo físico. En cuanto yo utilizo las leyes naturales me entrego a ellas al mismo tiempo, igualmente quedo sometido a las leyes lógicas en cuanto me sirvo de ellas. El sentido que mi manifestación debía tener, en determinadas circunstancias no es por completo el que tiene y no precisamente, porque yo no haya alcanzado a dar expresión al sentido querido, sino más bien, porque cada sentido es sólo una parte de sentido en una conexión de significados infinita, y (en esta conexión) provoca imprevisibles efectos. Esta conciencia de saberse uno inserto con todo pensamiento en una inmensa conexión de sentidos, en el mundo del "espíritu objetivo", en el que cada espíritu subjetivo es parte y miembro, es algo que nos enseña a ser modestos al par que nos eleva al infinito. 35

33 Ibidem, pp. 144 y ss.

34 Radbruch, Gustav, Rechtsphilosophie, 8a. ed., 1973, ed. por Erik Wolf, § 4, p. 119 (énfasis en el original); ed. de Ralf Dreier y Stanley Paulson, 2a. ed., 2003, p. 34 (versión española de José Medina Echavarría: Filosofía del derecho, Madrid, Editorial Revista de Derecho Privado, 1933).

35 Radbruch, op. cit., nota 34 (ed. Wolf, pp. 213, 216; ed. de Dreier y Paulson, pp. 113 y 115; versión española, § 15). 
El iusnaturalismo y el positivismo jurídico son mucho menos modestos, y buscan la armonía en mucho menor grado que Radbruch, y por ello son quizá más atractivos. Lo que hoy nos interesa solamente es saber si el iusnaturalismo o el positivismo jurídico son capaces de cimbrar la tesis de que "el derecho es cultura", o bien, si ambos son un tanto, por así decirlo, unilaterales. Bien visto, no existe "el" positivismo, así como tampoco existe "el" iusnaturalismo, sino que más bien hay respectivamente toda una familia de teorías más o menos positivistas y más o menos iusnaturalistas, y así, para unos Hobbes es positivista y para otros iusnaturalista. Por eso tenemos que hacer un planteamiento más grueso.

Para el positivismo el derecho es estatuto, voluntad, mandato. Ahora bien, el derecho no puede ser mera voluntad ni mero mandato, por el simple hecho de que entonces sería fuente de derecho la conminación a entregar el dinero por boca de un asaltante. Así, el derecho requiere, como minimo, instancias legítimas y aceptadas que sean las creadoras de derecho. Si estas instancias existen, entonces todo acto jurídico, sea una ley, un acto administrativo o una sentencia judicial, será derecho cuando y en la medida en que sea expedido por la instancia competente. Así visto, el mandato que tenían los soldados de la República Democrática Alemana de disparar a los fugitivos en la frontera con la otra Alemania, o las condiciones en las prisiones germanoorientales, eran derecho, aunque se tratara de una flagrante injusticia desde la perspectiva de la antigua República Federal de Alemania. ¿Significa esto entonces que el derecho es lo que determinan los poderosos en cada caso? Un positivismo genuino tiene que ver así las cosas $\mathrm{y}$, después de la reunificación, no sólo dejar impunes a los tiradores del muro, sino también a quienes les daban órdenes. Es evidente que ningún positivista aceptaría esta consecuencia. ${ }^{36}$ Pero si a la pregunta de por qué habría que castigar a

36 Sobre los "tiradores del muro" ha habido una intensa discusión. Cfr. por ejemplo Alexy, Robert, Mauerschützen. Zum Verhältnis von Recht, Moral und Straf- 
Erich Honecker contestara algo más que "porque nosotros los vencedores así lo hemos querido", entonces no sería un positivista puro. Sin embargo, no por ello se convertiría en iusnaturalista, y tampoco lo sería si dijera, como Radbruch, que el derecho de otra cultura es tan extremadamente injusto, desde el punto de vista de la nuestra, que "no es derecho", o dicho con más precisión: que no podemos permitir que sea válido como derecho, $37 \mathrm{y}$ por tanto, dejar impunes los hechos cometidos en su nombre si no queremos caer en contradicción con nosotros mismos.

Para el iusnaturalismo el derecho, o más precisamente el derecho correcto, está “dado", previamente, por la naturaleza. ${ }^{38}$ A nosotros nos corresponde solamente reconocerlo y aplicarlo, en su caso inclusive contra el derecho vigente e injusto de las leyes humanas. Consecuentemente, el iusnaturalismo de la Ilustración desarrolló sistemas completos a partir de la razón como naturaleza particular del ser humano, para luego confrontar este derecho racional con la maraña de los derechos medievales. Hoy es frecuente que por derecho natural se entiendan los derechos humanos inna-

barkeit, Hamburgo, Joachim Jungius Gesellschaft der Wissenschaften, 1993 (Berichte aus den Sitzungen, Jhg. 11, 2); Dreier, Horst, "Gustav Radbruch und die Mauerschützen”, Juristenzeitung, 1997, p. 421; Lege, Joachim, "Der Konkurs eines Unrechtsstaates", Der Staat, vol. 38, 1999, p. 1 (15). La llamada "fórmula de Radbruch" de 1946 ha desempeñado un papel en ella, incluso en la jurisprudencia del Tribunal Supremo Federal (BGHSt - Sentencias del Tribunal Supremo Federal en Materia Penal-vol. 39, pp. 1 y ss., (p. 15); vol. 40, pp. 218 y ss.; véase también BVerfGE — Sentencias del Tribunal Constitucional Federal Alemán— vol. 95, pp. 96 y ss., (p. 134)). Dicha fórmula reza: "El conflicto entre la justicia y la seguridad jurídica podría solucionarse en el sentido de que el derecho garantizado por la ley y el poder tendría también primacía cuando fuera injusto e inoportuno por su contenido, a menos que la contradicción entre la ley positiva con la justicia alcanzara un grado a tal punto intolerable que la ley, como "derecho incorrecto", tuviera que ceder ante la justicia”. Radbruch, op. cit., nota 34 (ed. Wolf p. 345; ed. Dreier/Paulson, p. 216).

37 Así señalado de manera expresa en este sentido en la resolución del Tribunal Constitucional Federal alemán del 14 de febrero de 1968 -2BvR 557/62$B V e r f G E 23$, pp. 98 y ss., tesis 1 -nacionalidad de un judío emigrado-; al respecto, y con un mayor desarrollo, Schulte, Martin, "Geltung und Wirksamkeit des Rechts der Gesellschaft”, Rechtstheorie, vol. 35, 2004, p. 669 (672).

38 Höffe, Ottfried, Klaus Demmer y Alexander Hollerbach, artículo "Naturrecht”, en Staatslexikon, ed. por la Görres-Gesellschaft, 7a. ed., vol. 3, 1987, cols. 1296 y ss. 
tos. ¿Pero existen éstos verdaderamente "por naturaleza”? ¡Mira y observa! El ser humano en estado de naturaleza, es decir, sin cultura que lo modere, sin impulso hacia el bien, este hombre no es sólo el lobo del hombre, como dice Hobbes (homo est homini lupus, aunque en relación con los estados, no los individuos). Y mucho menos es el hombre un dios para el hombre: la frase homo est homini deus es aplicable, para Hobbes, apenas en el estado civil, es decir, en el Estado. ${ }^{39}$ En el estado de naturaleza el hombre es más bien para el hombre, y esto es algo que ni siquiera lo ha dicho así Hobbes, un ángel caído, un demonio, similar al de la civitas terrena de San Agustín. ${ }^{40} \mathrm{Y}$ no vale plantear la objeción de que el iusnaturalismo no se preocupa de cómo es el ser humano por naturaleza, sino de cuál derecho es válido por naturaleza (es decir, se trata de no caer en un error categórico). Porque, ¿quién decide, quis iudicabit, cuál "es" el derecho por naturaleza? Para muchas culturas está dado por naturaleza que las mujeres no tengan derechos, o tengan menos derechos. En Alemania se les otorgó el voto apenas en 1918 y eso por una circunstancia afortunada. ${ }^{41}$ En suma: los "derechos humanos innatos" no son sino una conquista de la cultura. Esto no quiere decir que la cultura en la que tienen su origen - el Occidente cristiano- sea mejor en todos sentidos, pues ella también tiene, a semejanza con los aztecas, sus lados oscuros: las cruzadas, los juicios contra las brujas, el tráfico de esclavos, las persecuciones de judios; en pocas palabras: el horror.

Si entendemos el derecho como cultura entonces estamos conscientes de este horror. ${ }^{42} \mathrm{El}$ estado de naturaleza no es algo que hayamos superado en la edad de piedra, sino una

39 Hobbes, Thomas, De cive (1647), dedicatoria.

40 Cfr. San Agustín, De civitate Dei (413-426), libros XII a XIV.

41 Rosenbusch, Ute, Der Weg zum Frauenwahlrecht in Deutschland, Baden-Baden, Nomos, 1998, especialmente pp. 457 y ss.

42 Puede ser que esta idea sea profundamente burguesa, si no "lübeckiana" (Lübeck es una ciudad hanseática del norte de Alemania). Cfr. Mann, Thomas, "Lübeck als geistige Lebensform” (1926), en Essays, vol. 3, 1994, pp. 16 (34 y s.); Radbruch también era originario de Lübeck. 
abstracción; es eterno, existe en el interior de todos nosotros, particularmente cuando los recursos se hacen escasos; tenemos que superarlo una y otra vez, y ello lo podemos mostrar, por ejemplo, a través del derecho de las técnicas biológicas y genéticas. ${ }^{43}$ Esta superación requiere, y en este sentido tiene razón el positivismo, de la voluntad, pero no de una voluntad desenfrenada, porque entonces estaríamos de nueva cuenta en el estado de naturaleza (como sucede con frecuencia, los extremos se tocan), sino que se necesita la combinación de la voluntad con la razón, de voluntas y de ratio. ${ }^{44} \mathrm{El}$ positivismo jurídico y el iusnaturalismo no hacen más que enfatizar alguno de estos dos polos. En realidad, ambos están siempre en combinación, y el resultado no es fruto del mero azar ni tampoco puro determinismo; no es arbitrario, pero tampoco necesario; en suma, es el resultado de la historia. El concepto filosófico técnico para esta situación es el de "contingencia" (del latín contingere, tocarse, suceder, pero también: lograrse). ${ }^{45}$ Para la escolástica era contingente la creación de Dios (también lo es para la teoría de la evolución). En la visión actual, es contingente sobre todo aquello que denominamos "cultura", nuestra "segunda naturaleza".

La tesis de que el derecho es un fenómeno de la cultura podría resultar plausible después de todo lo dicho, particularmente en sus dimensiones profundas. Ciertamente, parece una tesis poco emocionante dado que, desde un punto de vista descriptivo, no hay nada humano que no sea cultu-

43 Lege, Joachim. "Die Steuerung der Gentechnik durch das Recht”, en Kloepfer, Michael (ed.), Technikumsteuerung durch Recht. Rechtsfragen der Einführung der Gentechnik und des Ausstiegs aus der Atomenergie, Berlín, Duncker und Humblot, 2002, pp. 67 y ss.

44 Incluso para San Agustín, la ley eterna de Dios, la lex aeterna, no es mera voluntad, pero tampoco mera razón, sino que señala, con notable indecisión: "Lex vero aeterna est ratio vel voluntas Dei ordinem naturalem conservari iubens, perturbari vetans" ("En verdad la ley eterna es la razón o la voluntad de Dios que ordena conservar el orden natural y prohíbe perturbarlo"; Contra Faustum XXII, 27, citado por Böckenförde, Ernst-Wolfgang, Geschichte der Rechts- und Staatsphilosophie. Antike und Mittelalter, Tubinga, UTB, 2002, p. 197).

45 Para profundizar véase Hoering, Walter, artículo "Kontingenz", en Historisches Wörterbuch der Philosophie, vol. 4, 1976, col. 1027. 
ra. Sin embargo, desde el punto de vista normativo hay sin duda muchas cosas faltas de cultura, e incluso las culturas - como el derecho- pueden extinguirse. Por ello queremos regresar a las dos cuestiones derivadas de la gran pregunta, respecto de la cual la respuesta es que "el derecho es cultura”, y específicamente a la segunda: “¿qué necesita el derecho?". También a esta pregunta ya habiamos dado la respuesta: si es cultura, entonces el derecho requiere autonomía.

\section{El derecho requiere autonomía}

Lo que esto significa con precisión, es algo que difícilmente se puede señalar. El derecho no es solamente una forma específica de cultura, sino que existen, en cierto modo de acuerdo con la cultura global circundante, diversas culturas jurídicas. Los sistemas de precedentes judiciales y los de leyes codificadas, el derecho estatal pero también el praeter-estatal, como la lex mercatoria, y finalmente, si se quiere, el derecho "primitivo". Por ello resulta de hecho contingente cómo se exprese la autonomía en la respectiva cultura jurídica, cómo sea simbolizada: en una cultura no estatal puede ser el gorro de leopardo que el jefe de la tribu se pone en la cabeza el día que dedica a resolver conflictos, en otras culturas puede ser la judicatura profesional e independiente (con o sin peluca). En la época moderna es sobre todo la idea de la división de poderes en la que se manifiesta la autonomía del derecho, y no es casualidad que esta idea sea distinta en Locke respecto de Montesquieu y Kant.46 Aparte de estas contingencias, la exigencia de autonomía del derecho significa, sobre todo, cuatro cosas:

El primer aspecto es el reconocimiento de la legalidad propia (Eigen-Gesetzlichkeit) del derecho tal como se entien-

46 Sobre Locke, véase la nota 4, supra. Véase en Montesquieu, De l'esprit des lois (1748), libro XI, cap. 6, la conocida tripartición en legislativo, ejecutivo y judicial; igualmente en Kant, Immanuel, Metaphysik der Sitten. Rechtslehre (Metafísica de las costumbres. Doctrina del derecho), 2a. ed., 1798, § 45. 
de en la cultura respectiva y se entiende a sí misma. El derecho respectivo debe ser capaz de continuar por sí mismo su historia, ${ }^{47}$ ya sea en la tradición del case law, de la idea de la codificación o del derecho científico de los juristas. En Inglaterra, buena parte de la reserva que existe contra Europa parece consistir en que la Unión Europea impone algo ajeno y heterogéneo al derecho, tal como éste se ha desarrollado.

El segundo aspecto es el reconocimiento de la legalidad propia del derecho como forma especial de cultura. Esto se refiere primeramente y sobre todo a aquellos que actúan en nombre del derecho: quien se coloca el birrete del derecho, tiene que aceptar que al final salga algo distinto de lo planeado. Si no lo hace así, entonces el recurso al derecho es, en última instancia, hipocresía - "esta forma última, y la más abstrusa, del mal, en la que el mal se convierte en bien y el bien en mal"- (Hegel). ${ }^{48}$ Pero también hay que exigir de los demás, y sobre todo de la política, el respeto a la legalidad propia del derecho: si la política utiliza solamente al derecho como medio, y ya no como fin en sí mismo, entonces lesiona su dignidad, ${ }^{49}$ o si se quiere: la santidad del derecho. ${ }^{50} \mathrm{El}$ caso extremo son los procesos simulados, pero el diablo puede insinuarse de manera menos espectacular, como por ejemplo, cuando se instrumentaliza la moción de confianza a que se refiere el artículo 68 de la Ley Fundamental alemana para provocar la convocatoria a nuevas

47 Sobre la concepción del derecho como una chain novel, véase Dworkin, Ronald, Law's Empire, Cambridge, Mass., Harvard University Press, 1986, pp. 228 y ss.

48 Hegel, op. cit., nota 22, § 40, nota.

49 Cfr. Kant, Immanuel, Grundlegung zur Metaphysik der Sitten, 2a. ed., 1786, pp. 66 y ss. (Werkausgabe, vol. VII, 1974): "Obra de tal modo que uses la humanidad, tanto en tu persona como en la persona de cualquier otro, siempre como un fin al mismo tiempo y nunca solamente como un medio"; la vinculación con la dignidad en ibidem, pp. 74 y s., 76 y s.

50 Cfr. Hegel, op. cit., nota 22, § 30. 
elecciones. ${ }^{51}$ Lo que hay que considerar es que quien no recibe respeto, puede ser culpable de ello. Así, por ejemplo, cuando el derecho se niega a asumir responsabilidad por sus decisiones y prefiere apostar por el consenso, entonces dilapida su pretensión de respeto, y las decisiones se toman en otra parte. El derecho puede ser tan condescendiente que acabe festejando como un logrado compromiso lo que son soluciones jurídicamente contradictorias. Así, por ejemplo, la Ley alemana sobre Células Troncales ha prohibido la importación de células troncales embrionarias, a menos que hayan sido obtenidas lícitamente en el extranjero antes del 1o. de enero de 2002. ${ }^{52} \mathrm{Si}$ consideramos que lo que podría justificar la prohibición es la violación del artículo 10. de la Ley Fundamental por la obtención de células troncales embrionarias, entonces no se justifica la permisión del periodo previo. En cambio, si no se juzga que la obtención de células troncales embrionarias sea una violación de la dignidad humana, entonces no se justifica prohibir la importación. ${ }^{53}$ ¡Ay del jurista que participa en la formulación de esta clase de contradicciones!

Esto nos conduce al tercer aspecto. Quienes actúan a nombre del derecho deben aportar una cierta medida de ethos: el derecho demanda empeño; como insiste una y otra vez Alexander Hollerbach, hay que hacerse cargo de él, 54 y

51 Tribunal Constitucional Federal alemán (TCFA), sentencia del 25 de agosto de 2005 - BvE 4/05, 2 BvE 7/05, reproducida en www.bverfg.de; más al respecto en IV, 3 infra.

52 Ley para Asegurar la Protección del Embrión en Relación con la Importación y Utilización de Células Troncales Embrionales, del 28 de junio de 2002 (BGBl. I 2277), reformada por ley del 25 de noviembre de 2003 (BGBl. I 2304).

53 Lege, Joachim, "Das Recht der Bio- und Gentechnik", en Schulte, Martin (ed.), Handbuch des Technikrechts, Berlin, Springer, 2003, 669 y ss. (761 y s.), con mayores referencias; además, Enders, Christoph, "Würde- und Lebensschutz im Konfliktfeld von Biotechnologie und Fortpflanzungsmedizin”, Jura, 2003, p. 666.

54 Hollerbach, Alexander, "Reflexionen über Gerechtigkeit", en Brieskorn, Norbert y Müller, Johannes (eds.), Gerechtigkeit und soziale Ordnung. Festschrift für Walter Kerber, Friburgo de Brisgovia, Herder, 1996, pp. 42 y ss. (45); véase del mismo autor la voz "Rechtsethik", en Staatslexikon (nota 5), col. 692 (693); ambos textos también en Ausgewählte Schriften, cit., nota 5, pp. 63 y ss. (65 y s.), 83 y ss. (84). 
si bien no se puede exigir del jurista amor hacia el derecho, sí se puede esperar que no caiga en la venalidad. Tampoco es correcto que, siempre que no logra la mayoría necesaria para una reforma constitucional, la política obtenga de algún jurista el resultado deseado, vía la interpretación de la Constitución. Ya es tiempo de exigir más "honestidad constitucional". 55

Cuarto aspecto: autonomía del derecho significa que, en cuanto manifestación de la cultura, hay que tratarlo con cuidado. Hay que reconocerle al derecho espacios libres, en los cuales pueda "lograrse" la difícil interrelación entre voluntad y razón. ${ }^{56}$ Esto se refiere, por un lado, al trabajo con los textos jurídicos, sobre todo en las obras legislativas -en la Prusia de comienzos del siglo XX, todavía "un logro intelectual de peso, audaz y prudente, el fruto de algunas décadas de experiencia y de algunos años de ponderación y pulido insistentes, casi artísticos". 57 Además de lo anterior, el derecho no sólo debe entender algo de derecho, sino, como enfatiza también Hollerbach, debe entender sobre todo algo de la vida,58 de la "materia" a la que pretende regular, de los órdenes con los que se encuentra y los que desea crear. ${ }^{59}$ Por ello, el derecho requiere sobre todo tiempo:

55 Gramm, Christof, "Die Aufgaben der Bundeswehr und ihre Grenzen in der Verfassung", Neue Zeitschrift für Wehrrecht 2005, p. 113, en particular el apartado VI.

56 Sobre el "logro" como criterio de corrección, en general y en el derecho en particular, cfr. Lege, op. cit., nota 20, pp. 370 y ss., 582 y ss.

57 Haffner, Sebastian, Geschichte eines Deutschen, Munich-Stuttgart, DVA, 2002, p. 227.

58 Hollerbach, Alexander, voz "Rechtswissenschaft", en Staatslexikon (cit., nota 5), col. 757; igualmente en Ausgewählte Schriften, cit., nota 5, pp. 86 y ss. (94): a la hermenéutica del texto hay que agregar una hermenéutica de la situación de hecho y del caso (o si se quiere, una hermenéutica de la vida). De otro modo no es posible alcanzar la justicia del objeto (Sach- Gerechtigkeit). Véase Hollerbach, "Reflexionen...", cit., nota 54, pp. 47 y s. (pp. 63 y ss., 68 y s. de Ausgewählte Schriften, cit., nota 5).

59 Sobre la idea de orden, Hollerbach, Alexander, "Göttliches und Menschliches in der Ordnung der Kirche”, en Hollerbach, Alexander y Würtenberger, Thomas (eds.), Mensch und Recht. Festschrift für Erik Wolf zum 70. Geburtstag, Frankfurt a. M., Vittorio Klostermann, 1972, pp. 212 y ss.; véase del mismo autor "Reflexionen...", cit., nota 54; ambos textos en Ausgewählte Schriften, cit. nota 54, pp. 177 y ss., 63 y ss. (71 y s.). 
tiempo para internalizar todos los intereses, y tiempo para inventar nuevas estructuras, a saber, reglas que resuelvan los conflictos de manera tan evidente, que se puede estar en lo futuro satisfecho y con ello se ahorre tiempo. Por eso, a la larga resulta contraproducente 60 acelerar los procesos a cambio de ello. ${ }^{61}$ Casi le deseamos al derecho una especie de redescubrimiento de la lentitud, 62 también en los estudios jurídicos.

Sin embargo, ya sabemos que el tiempo es dinero. Además, el derecho no sólo cuesta tiempo sino también la aplicación de esfuerzo y trabajo, no sólo por el lado de los juristas, sino también de los participantes e interesados. ¿Será posible utilizar mejor estos recursos en otra parte? Así llegamos finalmente a la primera subpregunta de la gran pregunta: ¿necesitamos en verdad el derecho y la cultura?

\section{El DERECHO COMO BIEN DE LA CULTURA}

Los bienes de la cultura son definidos como "testimonios irrecuperables de la evolución espiritual e histórica que son de valor esencial para toda sociedad".63 $\mathrm{Si}$ el derecho no sólo es cultura, como ya lo hemos constatado, sino ya también ser un bien, un "bien de la cultura”, entonces tenemos

60 Sobre la aceleración de los procesos y el mejoramiento de las estructuras como dos métodos concurrentes para ahorrar tiempo, véase Luhmann, Niklas, Soziale Systeme, Frankfurt a. M., Suhrkamp, 1984, pp. 388 y ss. (versión española: Sistemas sociales. Lineamientos para una teoría general, México, UIA-Alianza Editorial, 1991, pp. 291 y ss.). Con las más diversas leyes de aceleración, la política jurídica de las últimas décadas ha apostado sobre todo por la primera posibilidad (sobre el derecho administrativo, véase Hufen, Friedhelm, Verwaltungsprozessrecht, 5a. ed., 2003, § 3, núms. marginales 5 y ss.).

61 Las malas leyes y sentencias, debido a que son superficiales, generan, como todos los malos productos, necesidad de mejoras, la que debe satisfacerse a costa de recursos de por sí escasos, de modo que éstos se vuelven más escasos aún. Cfr. también Hufen, op. cit., nota 60, § 3, núms. marginales 9 y ss., en relación con la sobrecarga cualitativa de los tribunales administrativos.

62 Otro libro de culto: Nadolny, S., Die Entdeckung der Langsamkeit, Munich, Piper, 1983 (versión española: El descubrimiento de la lentitud, Barcelona, Edhasa, s.f.).

63 Desde la perspectiva jurídica, el tratamiento amplio de Odendahl, Kerstin, Kulturgüterschutz, Tubinga, Mohr-Siebeck, 2005. 
que explicar en qué consiste su valor. Esto podría hacerse en cierto modo desde fuera: como hemos visto, el derecho cuesta algo, a saber, el empleo de trabajo y tiempo, sobre todo de tiempo para la reflexión. Sin embargo, este uso es rentable porque el derecho ofrece una gestión altamente eficiente del conflicto: la resolución de un conflicto concreto con ayuda de una regla abstracta resuelve ya futuros conflictos e inclusive puede evitarlos. Con ello se evitan o se minimizan los costos de los nuevos conflictos, ${ }^{64}$ y por ello la inversión en el derecho "se paga" en el largo plazo. No soy economista y no deseo entrar en terreno resbaloso; en lugar de ello voy a intentar mostrar que el derecho crea, quizá "posee", ciertos valores.

1. Para qué existe el derecho: paz, justicia, libertad

¿Cuál es el objetivo, el fin, el valor del derecho, aquello por lo cual existe (en griego: hou héneka)? También aquí podríamos encontrar toda una familia de respuestas; me limito a entresacar tres: paz, justicia y libertad.

(1) Una respuesta que podría ser susceptible de consenso general es la idea de que el derecho sirve a la paz (en este sentido, todos somos hobbesianos). Sin embargo, esto es válido sólo de modo indirecto: "El objetivo del derecho es la paz, el medio para lograrlo es la lucha”, dice Ihering en su famosa obra La lucha por el derecho. ${ }^{65} \mathrm{El}$ derecho no pretende la pacificación a cualquier precio, pues entonces sería sólo el derecho del más fuerte, sino sólo al "precio" de una decisión justa.

(2) Sorprendentemente, es muy debatida la cuestión de si la justicia es un asunto del derecho o un asunto de la mo-

64 Los conflictos son sistemas sociales que viven "parasitariamente" a costa de su entorno. Cfr. Luhmann, op. cit., nota 60, pp. 530 y ss.

65 Ihering, Rudolf von, Der Kampf um's Recht (conferencia 1872), 18a. ed. 1913, reimpr. 1992, p. 61 (versión española: La lucha por el derecho, México-Lima-Buenos Aires, Cajica, 1957). 
ral. El filósofo inglés del derecho H. L. A. Hart, por ejemplo, insistía en que había que distinguir entre el derecho como es y el derecho como debería ser. Este último es una cuestión de la justicia y, con ello, de la moral.66 Por el contrario, Gustav Radbruch enfatizó siempre que el derecho es el "conjunto de datos, cuyo sentido estriba en la realización de la idea del derecho", y que "la idea del derecho no puede ser otra que la justicia”. 67 También aquí y ahora hay que enfatizar que la justicia es justamente una tarea de los juristas. Para variar un antiguo slogan: " ¡Nosotros producimos justicia”!68 Si no nosotros, ¿entonces quiénes? Por justicia los políticos parecen entender, cada vez más, que hay que distribuir los recursos escasos de tal manera que de todos modos queden satisfechos todos los deseos. Por el contrario, la "justicia jurídica" 69 consiste en dar a todos las mismas reglas y así crear la misma libertad. De este modo creamos, como dice Hollerbach, una justicia en pequeños pasos ${ }^{70} \mathrm{y}$ en cierto modo una ayuda para la autoayuda.

(3) La libertad como valor del derecho es lo que menos tenemos presente en la actualidad. Hegel dice todavía, inmediatamente después de la cita sobre el zapatero: "El derecho se refiere a la libertad, lo más digno y sagrado en el hombre, que él mismo... debe conocer”. El ser humano puede y debe saber por sí mismo si le quedan bien los zapatos y si el derecho le "queda" bien. Y Kant define también el derecho a través de la libertad: "El derecho es el conjunto de las condiciones, bajo las cuales se puede unir el arbitrio de uno

66 Hart, Herbert Lionel Adolphus, "Der Positivismus und die Trennung von Recht und Moral”, en idem, Recht und Moral. Drei Aufsätze, ed. por Norbert Hoerster, Gotinga, Vandenhoeck und Ruprecht, 1971, pp. 14 y ss.

67 Radbruch, op. cit., nota 34, §§ 1 y 4 (ed. Wolf, pp. 91, 119 y s.; ed. Dreier/Paulson, pp. 11 y s., 34).

68 En los años setenta, el Ejército Federal alemán hacía propaganda con el slogan: “iNosotros producimos seguridad!”.

$69 \mathrm{Al}$ respecto, véase la reciente obra de Osterkamp, Thomas, Juristische Gerechtigkeit. Rechtswissenschaft jenseits von Positivismus und Naturrecht, Tubinga, Mohr-Siebeck, 2004.

70 Hollerbach, Alexander, voz "Gerechtigkeit II", en Staatslexikon, ed. por la Görres- Gesellschaft, 7a. ed., vol. 2, 1986, cols. 902 y s. 
con el de el otro conforme a una ley universal". ${ }^{71}$ Para nosotros, por el contrario, el derecho nos parece que es un instrumento de dominio que nos acarrea falta de libertad. ¿El derecho hace posible la libertad? ${ }^{72}$ ¿Qué acaso no la restringe primero?

\section{El derecho como cultura de la libertad}

El que hayamos perdido la noción del derecho como cultura de la libertad ${ }^{73}$ se debe quizá a que nuestra concepción de cultura en conjunto se ha polarizado de manera muy particular: ${ }^{74}$ por un lado, y para decirlo vulgarmente, la cultura se ha "colgado demasiado alto" - en las secciones culturales para intelectuales - y por el otro, "se ha colgado demasiado bajo" - bajo la figura de todos los intentos de exorcizar el aburrimiento del pueblo-. De igual modo, el derecho aparece entre nosotros, los alemanes, como excesivamente elevado por un lado: bajo la figura de la Ley Fundamental alemana, a la cual en ocasiones es un tanto penoso rendirle pleitesía, a ella y a nosotros mismos, como la mejor Constitución de todos los tiempos. Por otro lado, el derecho es todas estas cosas incómodas que día con día nos ponen de malas con sus regulaciones, formularios, peticiones, preceptos. Esta polarización es quizá consecuencia de la sociedad de los medios, para la cual cualquier cosa es o una sensación o algo aburrido. ${ }^{75}$ La polarización explica quizá

71 Kant, op. cit., nota 46, Einführung in die Rechtslehre, § B, p. 33.

72 Cfr. también Kloepfer, Michael, "Recht ermöglicht Technik", Natur und Recht 1997, p. 417.

73 Di Fabio, Udo, Die Kultur der Freiheit, Munich, C. H. Beck, 2005, apareció después de dictada la lección inaugural.

74 Esta es la tesis principal de Terry Eagleton, op. cit., nota 25, en especial p. 48.

75 Sobre la consecuencia véase ya Luhmann, Niklas, Ökologische Kommunikation, Opladen, Westdeutscher Verlag, 1986: la sociedad moderna genera a la vez un exceso y una falta de resonancia. Menos convincente es su opinión en Die Gesellschaft der Gesellschaft, Frankfurt a. M., Suhrkamp, 1998, vol. 2, pp. 1096 y ss., 1103 (versión española: La sociedad de la sociedad, México, Herder, 2007, pp. 868 y ss.), de que los medios de masas siguen el código información / no información, 
también que, por un lado, percibamos una juridificación creciente $^{76} \mathrm{y}$, por el otro, que el derecho y los juristas hayan perdido importancia en la sociedad y en las posiciones dirigentes, y que incluso se les haya marginado. ${ }^{77} \mathrm{El}$ filólogo inglés Terry Eagleton ha observado que es destino de todo lo oficialmente sagrado el ser puesto en el medio, por un lado, y el ser desplazado al margen, por el otro. ${ }^{78}$ Por ello podemos suponer que por eso y justamente el derecho ya sólo es oficialmente sagrado entre nosotros. (Esta hipótesis se vio confirmada recientemente por la disolución del Parlamento Federal alemán en 2005, la cual ha mostrado que ya no se toma en serio la autoridad del texto, de la Ley Fundamental, sino que se cumple con los sacramentos solamente pro forma). ${ }^{79}$

Si tomamos como punto de partida esta imagen polarizada del derecho, parece evidente que en realidad no necesitamos esta forma de la cultura. Aparte de los derechos fundamentales y humanos, así como de la democracia, el derecho es más bien la cultura de los aburridos, de la clase media burguesa, si no de todas las naturalezas débiles que se proponen ajustarse a las reglas. Terry Eagleton ha observado que con la religión sucede lo contrario, ya que está en condiciones de unir la alta cultura (la cultura como algo elevado y supremo) y la cultura cotidiana (la cultura como

porque lo que hace que cualquier información se convierta en relevante para los medios es su carácter de sensación.

76 Ya desde los años setenta. Véase, por ejemplo, Voigt, Rüdiger (ed.), Verrechtlichung, Analysen zu Funktion und Wirkung von Parlamentarisierung, Bürokratisierung und Justizialisierung sozialer, politischer und ökonomischer Prozesse, Königstein, Athenäum, 1980; Kübler, Friedrich (ed.), Verrechtlichung von Wirtschaft, Arbeit und sozialer Solidarität. Vergleichende Analysen, Baden-Baden, Nomos, 1984.

77 Huber, Peter Michael, “Der 'Bologna-Prozess' und seine Bedeutung für die deutsche Juristenausbildung”, European Journal of Legal Education, 2005, pp. 35 y ss. $(38,43)$.

78 Cfr. Eagleton, op. cit., nota 25, p. 47.

$79 \mathrm{Al}$ menos resulta consecuente el voto particular de la juez Gertrude Lübbe-Wolff. Tribunal Constitucional Federal alemán, sentencia del 25 de agosto de 2005 (nota 51), incisos 213 y ss. Cfr. también el diario Neue Zürcher Zeitung del 26 de agosto de 2005, p. 3: "un obstáculo que prácticamente ya no se toma en serio". 
forma de vida), de modo tal que, como él dice, los elitistas más grandes son al mismo tiempo los más grandes populistas. ${ }^{80}$ Pero, ¿y el derecho? ¡Cuánto más emocionante es la justicia revolucionaria en lugar del aburrido Estado de derecho!81 Quizá el derecho sea algo divino y sagrado, pero, como dice Ernst Bloch, el trasero de Dios es el aburrimiento. 82

Si nos atenemos, en cambio, a otro inglés, Arnold Toynbee, entonces el destino de una sociedad depende siempre de las minorías creadoras. ${ }^{83}$ Estas minorías poseen, sobre todo, una característica: son débiles. Pero, por el otro lado, si se les permite, son la elite futura, o mejor dicho, una parte de ellas es la elite futura. Desafortunadamente, no podemos saber de entrada cuál parte será la elite. Esto es un horror para todo político y para todo burócrata (especialmente para aquel que desea crear universidades de elite por decreto y mediante una rienda dorada). Para el derecho, como lo entendemos, es un hecho. Y por ello precisamente protege el derecho a los débiles. A ellos les corresponde desenvolverse con libertad y no ser obstaculizados por las elites actuales. In the long run, junto con la libertad de todos a quienes deja vivir en paz, el derecho protege en cierto modo la libertad de las futuras elites fructíferas. El derecho crea, para quienes no desean dejarse controlar desde arriba, los espacios libres necesarios para el desenvolvimiento creativo, espacios en la economía, por ejemplo, a través de la li-

80 Véase Eagleton, op. cit., nota 25, pp. 98, 157 y ss.

81 Cfr. Schlink, Bernhard, "Rechtsstaat und revolutionäre Gerechtigkeit", Neue Justiz 1994, p. 433.

82 "El trasero del diablo es el desasosiego, el aburrimiento es el trasero de Dios”. Cfr. Zudeick, Peter, Der Hintern des Teufels. Ernst Bloch - Leben und Werk, Böhl-Moos, Baden-Baden, Elster Verlag, 1985. Véase también Gramm, Christof, Zur Rechtsphilosophie Ernst Blochs, Pfaffenweiler, Centaurus, 1987.

83 Papa Benedicto XVI (Joseph Ratzinger), "Europa ist krank”, Cicero 5, 2005, p. 58 (65). Cfr. También Reichold, Hermann, "Arbeitsrecht in der Risikogesellschaft", en Heß, Burkhard (ed.), Wandel der Rechtsordnung, Tubinga, Siebeck-Mohr, 2003, pp. 65 y ss., con referencia a Carl Christian von Weizsäcker, Logik der Globalisierung, Gotinga, Vandenhoeck und Ruprecht, 1999: la fuerza innovadora de un sistema radical en la libertad de desenvolvimiento de las minorías. 
bertad de trabajo en lugar de la coacción corporativa; mediante la autonomía privada en lugar de la regulación; a través de la economía de mercado en lugar de los carteles estatales o privados; o espacios en la ciencia: las universidades como lugar y refugio de la libertad de cátedra e investigación. Detrás se encuentra la esperanza de que en tales espacios protegidos (en cierto modo son laboratorios) se habrá de imponer in the long run (como diría Peirce), ${ }^{84}$ y en un proceso de trial and error (como dirían Popper y Zippelius), 85 lo correcto, incluso lo imprescindible para la supervivencia. Pero no tenemos más que esta esperanza ${ }^{86}$ en el "borrascoso océano" de la razón y la historia, el cual Kant pone bellamente en contraste con las pequeñas "islas" del entendimiento. 87

\section{El derecho como algo bello}

Los enemigos del derecho, como Hitler, han sido frecuentemente también enemigos de la libertad. Por ello deberíamos estar siempre vigilantes y determinar si siempre hay algo bueno detrás de las múltiples demandas actuales de alternativas al derecho (o en el derecho), 88 por ejemplo, "conciliar en vez de juzgar" o "mediación". El diablo es tramposo, y por ello nunca entra dos veces por la misma puerta. ${ }^{89}$ Quizá lo mejor para enfrentarlo sea mostrar que el derecho no sólo es algo molesto sino también algo bello.

84 Peirce, Charles Sanders, "Some Consequences of Four Incapacities" (1868), en Collected Papers, ed. por Charles Hartshorne y Paul Weiss, Cambridge, Mass., 1931-1935, vol. 5, parágrafo 264 (citado habitualmente 5.264), p. 311 . Al respecto, véase Lege, op. cit., nota 20, pp. 104 y s., 118 y s., 192 y passim.

85 Véase la nota 7, supra.

86 Sobre el principio esperanza en Peirce, véase Lege, op. cit., nota 20, pp. 190, 290 y passim.

87 Kant, Immanuel, Kritik der reinen Vernunft, 2a. ed., 1787 (B), p. 294, Werkausgabe, vol. III, 1974.

$88 \mathrm{Al}$ respecto Seelmann, Kurt, Rechtsphilosophie. Grundrisse des Rechts, 3a. ed., Munich, C. H. Beck, 2004, §§ 1, 4, 13.

89 Böckenförde, Ernst-Wolfgang, "Diskussionsbeitrag”, Veröffentlichungen der Vereinigung der Deutschen Staatsrechtslehrer vol. 60, 2001, pp. 124 (126). 
¿Qué es lo bello del derecho? Tomemos la moción de confianza a que se refiere el artículo 68 de la Ley Fundamental alemana. Si en verdad fuéramos un Estado constitucional de derecho, el punto de partida primario no habría sido lo que quería el consenso de la política, es decir, la disolución del Parlamento, para preguntar después cómo podía lograrse esto jurídicamente, sino que, "abiertos al resultado", había que preguntar si lo que la política quería lograr era jurídicamente admisible. El texto autoritativo de la Ley Fundamental habría callado en primera instancia, pues no está prevista una facultad de autodisolución del Parlamento Federal. ${ }^{90}$ La disolución del Parlamento es una facultad del presidente, y los supuestos se encuentran en el artículo 68:

Si la petición del Canciller Federal de un voto de confianza no encuentra la aprobación de la mayoría de los miembros del Parlamento Federal, entonces el Presidente puede disolver el Parlamento a petición del Canciller Federal dentro de un plazo de veintiún días... Entre la petición y la votación deben haber transcurrido cuarenta y ocho horas.

La cuestión decisiva es saber si la moción de confianza que plantea el Canciller puede ser empleada como simple medio, si puede ser instrumentalizada para lograr el "objetivo" de la realización de nuevas elecciones. ${ }^{91}$ En contra habla, en primer término, el argumento de que, ante las experiencias con la Constitución de Weimar, la Ley Fundamental pretendía construir un Parlamento estable. ${ }^{92}$ Por ello, el Tri-

90 Sin embargo, véase, con referencia a los antecedentes del artículo 68 de la Ley Fundamental, el voto particular de Lübbe-Wolff (supra nota 51), inciso 239 y ss. A pesar de algunos intentos, no se incorporó una facultad de autodisolución en la Constitución después de 1983, y es posible pronosticar que las cosas permanecerán así después de la moción de censura de 2005; sobre la escasa voluntad del constituyente permanente para "dejar crecer" el texto constitucional, véase Gramm, op. cit., nota 55, V 2.

91 El voto particular del juez Hans-Joachim Jentsch es convincente en todos sentidos. TCFA (cit., nota 51), incisos 188 y ss., especialmente los incisos 205 y ss.

92 El resultado de las elecciones el 18 de septiembre de 2005 confirmó también que la instrumentalización de la moción de confianza conduce a la inestabilidad política (Jentsch, TCFA, cit., nota 51, inciso 209): las mayorías en el Parlamento 
bunal Constitucional Federal alemán (TCFA) ya había reconocido en 1983, con buenas razones, ${ }^{93}$ que la moción de confianza solamente es admisible cuando existe una verdadera crisis de gobierno; dicho con otras palabras, cuando el canciller Federal no cuenta con el respaldo de una mayoría estable en el Parlamento. De otro modo, en presencia justamente de una mayoría estable, el Canciller tendría el poder de disolver el Parlamento a causa de cualquier objetivo arbitrario, como por ejemplo, para poner fin a la incómoda labor de una comisión investigadora, ${ }^{94}$ o porque el barómetro político le promete una mayoría absoluta en una nueva elección.

Lo bello del derecho es que con la frase "La moción de confianza presupone una genuina crisis de gobierno" hay claridad de una vez por todas. Lo bello en la política es que siempre se puede volver a negociar todo. Desafortunadamente, en 1983 el TCFA construyó una puerta trasera: la existencia de una genuina crisis de gobierno es algo que el Tribunal podía verificar sólo de manera limitada, y el canciller - es decir, la política- tenía un margen para juzgar esta cuestión. ${ }^{95}$ De este modo fue posible entonces, a pesar de que existían severas reservas, permitir la disolución del Parlamento Federal. Para las naturalezas jurídicas refinadas, la señal del Tribunal era de todos modos clara: no lo vamos a permitir una segunda ocasión. ${ }^{96}$ Pero es evidente que las naturalezas políticas aprendieron algo distinto de la sentencia: cuando lleguemos a la hora de la verdad, el dere-

Federal se harian todavía más inestables que antes, y si la Gran Coalición entre la Unión Cristiano-Demócrata (CDU) y el Partido Socialdemócrata (SPD) resultante fue ventajosa, ya lo determinará la historia. Bonn no era Weimar (véase también la nota 16, supra), pero ¿no va Berlín en la misma dirección?

93 TCFA, sentencia del 16 de febrero de 1983 -BvE 1, 2, 3, 4/83, BVerfGE 62, pp. 36 y ss.: la así llamada situación inicial material.

94 Sobre la llamada Comisión investigadora de las visas, véase la resolución del TCFA del 15 de junio de 2005 -2 BvQ 18/05- publicada en www.bverfg.de: obligación de continuar de inmediato la labor de la comisión.

95 BVerfGE 62, pp. 50 y s.

96 El canciller Helmut Kohl así lo entendió y por ello bloqueó la demanda de nuevas elecciones con motivo de la unificación alemana. 
cho va a tener dificultades para poner límites a la política y va a dejarse instrumentalizar. Esto se confirmó en 2005.97

Vamos entonces a retener la siguiente conclusión: lo bello del derecho es que crea claridad. En esta medida es que su estilo puede ser incluso de utilidad para los científicos naturales. Nadie menos que Albert Einstein reconoció alguna vez haber aprendido disciplina mental gracias a su actividad en la Oficina suiza de Patentes, y en particular, haber aprendido a introducirse sistemáticamente en otras posiciones. ${ }^{98}$ A la pregunta “¿necesitamos el derecho?” deberíamos contestar: sí, si queremos claridad en la vida social. Y deberíamos querer esta claridad, porque la elevada complejidad, siguiendo libremente a Maquiavelo, 99 sirve predominantemente a los poderosos y los astutos.

\section{RESUMEN Y OSERVACIONES FINALES}

Hemos seguido un camino tortuoso: el "derecho" y la "cultura" son conceptos que designan a familias completas de fenómenos. Después hemos recordado que la historia de familia de nuestra cultura jurídica es, en su idea, una historia de libertad, una historia de protección de los débiles y

97 TCFA (cit., nota 51). - Bien vistas las cosas, la instrumentalización fue más drástica de lo que permiten entender los considerandos de la sentencia: el objetivo principal de la "convocatoria" a nuevas elecciones por el canciller mediático Gerhard Schröder era, evidentemente, desplazar del primer lugar en los titulares de prensa la derrota del Partido Socialdemócrata (SPD) en las elecciones regionales de Renania del Norte-Westfalia. Esto lo logró, incluso en el diario conservador Frankfurter Allgemeine Zeitung (del 23 de mayo de 2005). - A favor de que la convocatoria a elecciones era tal sensación ( $c f r$. la nota 75, supra) habla, además, el hecho de que hasta entonces no habia habido una verdadera crisis parlamentaria de gobierno ( $c f r$. el voto particular de Jentsch, TCFA, cit., nota 51, incisos 197, 200, 211). Resolver la crisis de un partido no es el propósito del artículo 68 de la Ley Fundamental, y mucho menos a costa de la estabilidad del sistema político ( $c f r$. cit., nota 92).

98 Cfr. la pieza de exposición correspondiente en el Museo de Einstein en Berna; en las biografias de Einstein, hasta donde puede verse, hay poco al respecto; de todos modos una referencia breve en http://www.einsteingalerie.de/bio/patent. html (consultada el 31 de octubre de 2005).

99 Nicolás Maquiavelo, Il Principe (1532), cap. XVIII, haciendo referencia a los leones y los zorros. 
los honestos frente a los astutos y los poderosos. Deberíamos hacer todo el esfuerzo posible para continuar esta historia. Y para ello no es necesario que nos entendamos igualmente bien con todos los miembros de la familia.

En toda investigación quedan siempre un par de pensamientos que nos hubiera gustado introducir. Con algunos de ellos quiero concluir.

Habíamos dicho al principio que el derecho se presenta al observador externo más bien como aburrido. Cuán falso es esto lo sabe cualquiera que haya llevado un proceso en causa propia (yo lo recomiendo a todos los estudiantes). Luchar por el derecho propio es un asunto altamente emocionante, y podemos estar contentos de no tener que hacerlo todos los días. Cuando tenemos que hacerlo a diario entonces es desgastante, y ese parece ser el problema con la creciente juridificación.

En realidad, aquello que denominamos juridificación es más bien algo muy diferente, esto es, excesiva burocratización. Que habitualmente confundamos ambas cosas puede deberse a que, como buenos súbditos alemanes, no podemos distinguir entre Estado y derecho. La burocracia, empero, es lo contrario del derecho, esto es, control por el Estado, y podemos estar contentos de que al menos esté sometida al derecho. El Rechtsstaat (Estado de derecho) - este Plan B típicamente alemán, concebido en el siglo XIX a falta de democracia- es, en sus orígenes, justamente y sobre todo, control del Estado de bienestar burocrático.

Resulta evidente que nuestra sociedad sólo está muy secundariamente interesada en el derecho. Esto se debe, quizá, a que no está interesada en la libertad, sino en el funcionamiento. O, en palabras de Kant y Hegel: no en la moralidad, sino en la felicidad. Cuando incluso el derecho se interesa con más frecuencia por este contexto que por su propio texto, no es de sorprender que sea dominado por aquél. Por ello, una última vez: ¿necesitamos el derecho? Sí, porque es un pedazo de cultura del que tenemos gran necesidad. 